AperTO - Archivio Istituzionale Open Access dell'Università di Torino

\begin{abstract}
Identification and characterization of Alternaria species causing leaf spot on cabbage, cauliflower, wild and cultivated rocket by using molecular and morphological features and mycotoxin production
\end{abstract}

This is the author's manuscript

Original Citation:

Availability:

This version is available http://hdl.handle.net/2318/1664973

since 2018-11-02T12:11:47Z

Published version:

DOI:10.1007/s10658-017-1190-0

Terms of use:

Open Access

Anyone can freely access the full text of works made available as "Open Access". Works made available under a Creative Commons license can be used according to the terms and conditions of said license. Use of all other works requires consent of the right holder (author or publisher) if not exempted from copyright protection by the applicable law. 
This is the author's final version of the contribution published as:

Ilenia Siciliano, Giovanna Gilardi, Giuseppe Ortu, Ulrich Gisi, Maria Lodovica Gullino Angelo Garibaldi

Identification and characterization of Alternaria species causing leaf spot on cabbage, cauliflower, wild and cultivated rocket by using molecular and morphological features and mycotoxin production, European Journal of Plant Pathology, 149, 2, 401-413, doi.org/10.1007/s10658-017-1190-0.

The publisher's version is available at:

https://link.springer.com/content/pdf/10.1007\%2Fs10658-017-1190-0.pdf

When citing, please refer to the published version.

This full text was downloaded from iris-Aperto: https://iris.unito.it/

\section{inis-AperTO}




\title{
Identification and characterization of Alternaria species causing leaf spot on cabbage, cauliflower, wild and cultivated rocket by using molecular and morphological features and mycotoxin production
}

\author{
Siciliano Ilenia ${ }^{1}$, Giovanna Gilardi' ${ }^{1}$ Giuseppe Ortu $^{1}$, Ulrich Gisi ${ }^{1}$, Maria Lodovica Gullino ${ }^{1,2}$, Angelo \\ Garibaldi $^{1}$
}

${ }^{1}$ Agroinnova - Centre of Competence for the Innovation in the Agro-Environmental Sector, University of Turin, Largo Paolo Braccini 2, 10095 Grugliasco, Turin, Italy.

${ }^{2}$ DISAFA - Dipartimento di Scienze Agrarie, Forestali e Alimentari, University of Turin, Largo Paolo Braccini 2, 10095 Grugliasco, Turin, Italy

Corresponding Author: e-mail: ilenia.siciliano@unito.it, Tel.: +390116708546

\begin{abstract}
Alternaria species are common pathogens of fruit and vegetables able to produce secondary metabolites potentially affecting human health. Twenty-nine isolates obtained from cabbage, cauliflower, wild and cultivated rocket were characterized and identified based on sporulation pattern and virulence; the phylogenetic analysis was based on the $\beta$-tubulin gene. Isolates were identified as A. alternata, A. tenuissima, A. arborescens, A. brassicicola and A. japonica. Pathogenicity was evaluated on plants under greenhouse conditions. Two isolates showed low level of virulence on cultivated rocket while the other isolates showed medium or high level of virulence. Isolates were also characterized for their mycotoxin production on a modified Czapek-Dox medium. Production of the five Alternaria toxins, tenuazonic acid, alternariol, alternariol monomethyl ether, altenuene and tentoxin were evaluated. Under these conditions, about $80 \%$ of the isolates showed the ability to produce at least one mycotoxin.
\end{abstract}

Key words: Crucifers, toxins, leaf spot, tenuazonic acid.

\section{Acknowledgements}

Work supported by the European Community's Seventh Framework Programme (FP7/2007-2013) under grant agreement n. 261752, PLANTFOODSEC "Plant and Food Biosecurity, Network of Excellence”.

\section{inis-AperTO}




\section{Introduction}

Most Alternaria species are saprophytes and ubiquitous in the environment, however some are plant pathogenic, inducing diseases on a large variety of economically important crops like cereals, oil-crops, vegetables and fruits (Pitt and Hocking, 1997). Most of Alternaria spp. produce chains of conidia with transverse and longitudinal septa, with a tapering apical cell. Conidial size, presence and size of a beak, the pattern of catenation and longitudinal and transverse septation are key taxonomic features for this genus (Joly 1964; Ellis 1971 and 1976 , Simmons 1992). Simmons (1992) proposed different species groups each with a typified representative, e.g. the Alternata group with small, catenate spores, while the porri species-group has large, long-beaked, non-catenate spores. Other species-groups include the brassicicola, the cheiranthi, the infectoria, and the tenuissima group (Simmons 1995, Woudenberg et al., 2015). In addition, some Alternaria spp. have a clinical significance producing toxic secondary metabolites that are involved in cancer development in mammals (Ostry 2008). Alternaria toxins can be divided into five different chemical classes: dibenzo- $\alpha$-pyrones; tetramic acid derivatives; perylenes; AAL-toxins (abbreviation for A. alternata f. sp. lycopersici toxins) and a class containing miscellaneous structures. A. alternata in particular is also known as an human pathogen in immunocompromised patients (Rossman 1996). Furthermore, Alternaria spores are well known as one of the most important airborne allergens (Thomma 2003). Alternaria diseases of crucifers are mainly caused by two species, A. brassicicola, and A. brassicae, and occasionally also by A. alternata. Depending on the species involved, the symptoms on crucifers are referred to as black, grey or dark leaf spot. Brassica hosts can be affected in all stages of growth and typical symptoms include black necrotic lesions surrounded by chlorotic areas on seedlings, leaves, stems and siliquae (Neergaard 1945; Humpherson-Jones 1989; Mac Kinon et al., 1999). Spots on leaf caused by A. brassicicola are generally similar to those caused by A. brassicae except that the lesions are gray-black in colour (Kolte 1987; Verma and Saharan, 1994). Spots can vary in size from 1.1 to $3.0 \mathrm{~mm}$ dark circular spots, when young, to black, brown or tan spots from 5 to $7.5 \mathrm{~cm}$ when older (Mac Kinon et al., 1999; Singh et al., 2012). Yellow halos may or may not surround leaf lesions. Larger spots may have a dark green-black coloration of fuzzy growth in the spots, usually concentrated in the center (Neergaard 1945). A. japonica has been reported on cultivated and wild rocket (Garibaldi et al., 2011), mainly as seed infection, causing reduced germination and seedling vigour, in addition to pre- and post-emergence damping-off (Gilardi et al., 2014). Symptoms caused by $A$. japonica on wild and cultivated rocket are usually black-brown lesions, 1 to $30 \mathrm{~mm}$ in diameter, which progressively turned black. Lesions usually start on the upper side of older leaves at the leaf 
margins and tips and developed a yellow halo. Eventually, lesions also affect leaf veins and stems (Garibaldi et al., 2011). However, A. japonica is not as widespread as A. brassicicola (CABI 2007; Humpherson-Jones 2007).

The present work was aimed at studying the variability within Alternaria isolates originating from different Brassica host plants and contaminated seeds, by using molecular and morphological characteristics, pathogenicity, virulence and mycotoxin production.

\section{Materials and Methods}

\section{Isolates collection}

Alternaria spp. were isolated from diseased wild and cultivated rocket and Brassica (cabbage, cauliflower) plants (15 isolates) and infected seeds (14 isolates) listed in Tables 1 and 2. Alternaria isolates were obtained by plating infected tissue (from wild and cultivated rocket, cabbage and cauliflower) onto Potato Dextrose Agar (PDA) medium, incubated at $25^{\circ} \mathrm{C}$ for 7 days. Isolates from seeds were obtained by testing different seed samples; 400 seeds per seed sample were placed on Petri plates (10 seeds/plate) as described by Maude and HumphersonJones (1980). Isolations were made from seeds either non disinfected or surface disinfected for 1 min in $1 \%$ sodium hypochlorite, washed in sterile water for $5 \mathrm{~min}$ and dried under a sterile hood. The Petri dishes were incubated at $22^{\circ} \mathrm{C}$ in $12 \mathrm{~h}$ light and $12 \mathrm{~h}$ darkness at 75\% R.H. for 7-10 days. The fungal colonies developing from seeds, morphologically identified as Alternaria sp. were transferred from Potato Dextrose Agar to Potato Carrot Agar (PCA).

After incubation, the isolates were transferred onto Potato Carrot Agar (PCA) medium amended with $0.5 \mathrm{mg} / \mathrm{ml}$ streptomycin sulphate, and incubated for 7 days at $25^{\circ} \mathrm{C}$. Single-spore cultures were prepared for each isolate by dilution of conidial suspension; about 50 conidia were plated on PDA medium. Germinated conidia were picked under the stereomicroscope and transferred again to PDA plates. The different isolates were maintained on PDA at $8{ }^{\circ} \mathrm{C}$. Isolates were re-grown on PCA at $25{ }^{\circ} \mathrm{C}$ for 10 days immediately before being tested for their pathogenicity/virulence.

\section{Pathogenicity assay in host plants}

The virulence of isolates, obtained from leaves and seeds, was tested on the host plants of origin. The plants, grown in pots, were inoculated, when 30-40 day-old, by spaying leaves with a conidial suspension at $1-5 \times 10^{5}$ conidia/ml. Inoculated plants were covered with plastic bags for 5-7 days and kept in greenhouse and/or in 
growth chambers at $25 \pm 1^{\circ} \mathrm{C}$. Ten to fifteen days after artificial inoculation, the percentage of infected leaf area of ten leaves per plant was estimated by using a disease index scale ranging from 0 to 100 . Isolates tested were classified as non-pathogenic (NP); low virulent: 10-30\% leaf necrosis (L); moderately virulent 31-60\% leaf necrosis (M); and highly virulent: 61-100\% (H) (Van der Waals et al., 2004).

\section{DNA extraction}

DNA extraction was carried out using the NucleoSpin Plant kit (Macherey-Nagel GmbH and Co., Duren, DE, USA), according to the manufacturer's instructions. Fresh mycelium was scraped from the surface of the colony and transferred into a $2 \mathrm{~mL}$ tube containing $400 \mu \mathrm{l}$ of lysis buffer and two tungsten beads (Qiagen Stainless Steel Beads, $5 \mathrm{~mm}$ ). Mycelium was homogenized using Qiagen TissueLyser for $3 \mathrm{~min}$ at 28 repetitions per minute; the lysate obtained was used for DNA extraction. DNA concentration was measured using a NanoDrop spectrophotometer and stored at $-20^{\circ} \mathrm{C}$ until further use.

\section{PCR amplification}

Amplification of $\beta$-tubulin was performed with the primers T1 5'-AACATGCGTGAGATTGTAAGT-3' (O'Donnell and Cigelnik, 1997) and Beta-tub-2 5'-ATCATGTTCTTGGGGTCGAA-3' (Peever et al., 2004) able to produce a 1100 bp amplicon. PCR reactions were performed using a T100 Thermal Cycler (Biorad) in a $20 \mu \mathrm{l}$ reaction mixture containing: $30 \mathrm{ng} / \mu \mathrm{L}$ of genomic DNA, $1 \mu \mathrm{L}(10 \mu \mathrm{M}$ stock, Invitrogen) of each primer, 1 unit of Taq DNA Polymerase (Qiagen), $2 \mu \mathrm{L}$ of PCR buffer (10X, Qiagen), $1 \mu \mathrm{L}$ of dNTPs (10 $\mu \mathrm{M}, \mathrm{VWR}$ ), and $0.8 \mu \mathrm{L}$ of $\mathrm{MgCl}_{2}(25$ $\mathrm{mM}$, Qiagen). The cycling conditions included an initial denaturing step at $94{ }^{\circ} \mathrm{C}$ for 5 min, followed by 35 cycles of denaturation at $94^{\circ} \mathrm{C}$ for $1 \mathrm{~min}$, annealing at $60{ }^{\circ} \mathrm{C}$ for $1 \mathrm{~min}$, extension at $72{ }^{\circ} \mathrm{C}$ for $2 \mathrm{~min}$, and final extension at $72{ }^{\circ} \mathrm{C}$ for $7 \mathrm{~min}$. A negative control (no template DNA) was included in all experiments. Amplifications were verified by electrophoresis on $0.8 \%$ agarose gel (Agarose D-1 LOW EEO, Eppendorf). After purification with QIAquick PCR purification kit (Qiagen), PCR products were measured using a NanoDrop spectrophotometer and sent to BMR genomics sequencing service (http://www.bmr-genomics.it/). Sequence contigs were assembled using DNAbaser software, and sequences were deposited at GenBank with accession numbers reported in Table 3.

\section{Alignment and phylogenetic analysis}

inis-AperTO 
Similarity searches (blastn, default parameters) were performed for all sequences. The sequences obtained were used for CLUSTALW multiple sequence alignments through MEGA6 software set to default parameters. Manual corrections were performed for each alignment in order to delete trimmer regions and incomplete sequences were discarded. Phylogenetic tree was constructed with MEGA6 (Tamura et al., 2007) using Maximum Likelihood method with 1000 bootstrap repeats and pairwise deletion. The evolutionary distances were computed using the Kimura 2-parameter model method and were given as units of the number of base substitutions per site. In each analysis sequences derived from reference Alternaria isolates obtained from the CBS-KNAW Fungal Biodiversity Centre (http://www.cbs.knaw.nl/) were included together with the sequence of Pleospora herbarum (CBS 191.86) used as outgroup (Woudenberg et al., 2013).

\section{Morphological evaluation}

The Alternaria monoconidial isolates were grown in Petri dishes with PCA media amended with streptomycin sulphate $(25 \mathrm{mg} / \mathrm{L})$ as reported by Simmons et al. (2007). Isolates were maintained in growth chambers with cool white fluorescent illumination at $23^{\circ} \mathrm{C}$ and $10 / 14 \mathrm{~h}$ light/dark cycle for 7 days. The observations of conidia morphology were carried out with a NIKON (Eclipse55t) microscope at 40x magnification. Conidial characteristics, body and beak length, shape, and number of longitudinal and transverse septa of twenty conidia per isolate were measured. The type of sporulation was evaluated under Stereo microscope (Leica M165C) by considering the length of conidial chains and type, if present, of branching.

\section{Secondary metabolites production}

Production of secondary metabolites was tested by growing isolates on a modified Czapek-Dox liquid medium according to Brzonkalik et al. (2011). Cultures were inoculated with three mycelial plugs in $20 \mathrm{~mL}$. All cultures were performed in triplicate and statically incubated in the dark at $28^{\circ} \mathrm{C}$. After 8 days, cultures were filtered and the clear medium was analyzed.

\section{Chemicals and standard preparation}

Standards of tenuazonic acid ( $\mathrm{TeA}$ ) copper salt from A. alternata (purity $\geq 98 \%$ ), alternariol (AOH) from Alternaria spp. (purity $\geq 94 \%$ ), alternariol monomethylether (AME) from Alternaria alternata (purity $\geq 98 \%$ ), altenuene (ALT) from Alternaria spp. (purity $\geq 98 \%$ ) and tentoxin (TEN) from Alternaria tenuis (purity $\geq 99 \%$ )

\section{ins-AperTO}


were purchased from Sigma-Aldrich (St Louis, MO, USA) in crystallized form. For each mycotoxin, a stock solution of $1000 \mu \mathrm{g} / \mathrm{mL}$ and a working solution of $10 \mu \mathrm{g} / \mathrm{mL}$ were prepared in methanol and kept at $-20{ }^{\circ} \mathrm{C}$. Standard solutions for HPLC calibration and for addition experiment were prepared by diluting the working solution in mobile phase $\left(\mathrm{H}_{2} \mathrm{O}: \mathrm{CH}_{3} \mathrm{OH} 6: 4\right.$ both with $\left.\mathrm{NH}_{4} \mathrm{HCO}_{3} 2 \mathrm{mM}\right)$.

\section{Extraction of secondary metabolites from fungal cultures}

Alternaria mycotoxins were extracted by liquid-liquid extraction. Each sample was adjusted to $\mathrm{pH} 2$ with $\mathrm{HCl}$, and an aliquot $(5 \mathrm{~mL})$ was transferred in a separating funnel. Ten $\mathrm{mL}$ of dichloromethane was added three times, and the mixture was shaken for $1 \mathrm{~min}$, then the lower dichloromethane extracts were collected in a flask. The final extract was evaporated to dryness in a rotary evaporator at $35{ }^{\circ} \mathrm{C}$. The residue was dissolved in $1 \mathrm{~mL}$ of $\mathrm{H}_{2} \mathrm{O}: \mathrm{CH}_{3} \mathrm{OH}$ 1:1 for the HPLC-MS/MS analysis.

\section{Analysis of secondary metabolites}

Chromatographic separation was carried out using a 1260 Agilent Technologies system consisting of a binary pump and a vacuum degasser, connected to a Varian autosampler Model 410 Prostar (Hansen Way, CA, USA) equipped with a $20 \mu \mathrm{L}$ loop. The separation was performed using a Kinetex PFP (100 x $2.10 \mathrm{~mm} 2.6 \mu$, Phenomenex) under a flow of $200 \mu \mathrm{L} / \mathrm{min}$ and with a temperature set at $35^{\circ} \mathrm{C}$. Solvent $\mathrm{A}$ was $\mathrm{H}_{2} \mathrm{O}$ with $2 \mathrm{mM}$ $\mathrm{NH}_{4} \mathrm{HCO}_{3}$, solvent B was $\mathrm{CH}_{3} \mathrm{OH}$ with $2 \mathrm{mM} \mathrm{NH}_{4} \mathrm{HCO}_{3}$. A linear gradient from $40 \%$ to $100 \%$ of solvent $\mathrm{B}$ in $12 \mathrm{~min}$ was used. Detection was done by using Varian 310-MS TQ Mass Spectrometer equipped with an electrospray (ESI) ion source operating in negative ion mode. For the Multiple Reaction Monitoring (MRM) experiments two transitions were selected for each compound. MRM transition used for quantification were m/z 196>139 CE 20V for TeA, m/z 257>213 CE 22V for AME, m/z 271>256 CE 22V for AOH, m/z 291>229 CE 12V for ALT, and m/z $413>271$ CE $16 \mathrm{~V}$ for TEN.

\section{Results}

\section{Pathogenicity assay}

First Alternaria symptoms were observed on old leaves. All isolates were pathogenic, but expressed different degrees of virulence on their host of origin (Table 4). Isolates Ruc PMP8 and Ruc PMP9 showed a low virulence,

\section{inis-AperTO}


all other isolates were moderately virulent (18 isolates) or highly virulent ( 8 isolates). There was no correlation between degree of virulence and host plants and /or Alternaria species.

\section{Phylogenetic analysis}

Sequence analysis of $\beta$-tubulin gene as molecular marker showed a Maximum Likelihood tree with 4 different Alternaria clades (Fig. 1). The first clade included isolates identified by sporulation pattern as $A$. alternata, $A$. arborescens and A. tenuissima. This first clade also included the reference strains. The second clade included only the Ruc PMP 4 isolate with a reference strain of $A$. brassicicola while the third clade represent the $A$. brassicae reference strain. In the last group, we found all isolates with sporulation pattern close to A. japonica.

\section{Morphological evaluation}

On PCA medium all isolates tested showed moderate to high sporulation with the exceptions that did not produce any conidia (Table 5). Isolates from seeds of wild rocket, 37Q-16NL, 38Q-1NL, 38Q-9 NL, 38Q-19NL, 43Q-1L showed dark colonies. The presence of numerous, intercalary chains of hyphal chlamydospores of 8.917.2 (mean 12.58) $\mu \mathrm{m}$ in length were easily recognized. Ruc PMP4 showed the same conidial length to those identified as A. japonica, but had fewer longitudinal septa and did not show any chlamydospores.

Isolates Ruc 5/10, Ruc 9/10, Ruc 12/10 showed a conidia chain length ranging from 12 to 37.6 (mean 29.3) $\mu$ m, with 3-8 transversal septa, while occasionally longitudinal septa were present. Young conidia were verrucose. Conidia were produced in branched chains with long primary conidiophores. Those characters correspond to $A$. arborescens morphotype.

For isolates Cav 3/10, Cav 12/10, Cav 15/10, Ruc 5/10 and Ruc 13/10, conidia were in chains of 7 to 20 elements. Mature conidia were golden brown and showed frequently a median septum, with a total body length ranging from 19.0 to 50.8 (mean $34.4 \mu \mathrm{m}$ ). Those characters correspond to A. tenuissima morphotype. Conidia of Cav 7/10 and Ruc PMP 19 were clearly smaller than the previously described isolates and produced mature conidia with a body length of 16.6 to 34.1 (mean $27.0 \mu \mathrm{m}$ ) in chains of up of 20 units, which correspond to $A$. brassicinae morphotype. Alternaria isolates coded Ruc 2/10, Ruc PMP 12, and Ruc PMP 9 showed conidia chains with lateral branches with a conidia size ranging from 16.7 to 40.1 (mean $27.7 \mu \mathrm{m}$ ).

Average size of conidia of Alternaria isolates varied within a broad range (Table 5). The length of conidia body and beak, used to draw an approximate boundary line among the Alternaria species identified in the present

\section{ins-AperTO}


study, provided evidence of a good correlations among the morphological parameters and the Alternaria species (Figure 2). Moreover, the identification performed by sporulation pattern yielded a good correspondence to the clustering in the phylogenic tree.

\section{Production of secondary metabolites}

The analytes were investigated using the external calibration method, and a calibration curve was built for each analyte. Good linearity was obtained for all analytes $\left(\mathrm{R}^{2}>0.999\right)$. Recovery experiments were done spiking the matrix before extractions with a standard solution at $100 \mu \mathrm{g} / \mathrm{L}$ for each mycotoxin. The calculated recovery ranged between 80 and $100 \%$. TeA was the main mycotoxin produced and was detected in more than $80 \%$ of analyzed Alternaria isolates. Benzopyrone derivatives, AOH, AME, and ALT, were identified in more than $50 \%$ of samples. TEN was produced only by four isolates (Cav 3/10, Cav 12/10, Ruc 9/10 and Ruc 12/10) (Table 4). As showed in Fig. 3 samples in clade 1 and 4 have a different production. Only two samples (Ruc PMP 19J and 38Q1NL) in clade 4 produced mycotoxins, while all the strains in clade 1 produce at least one mycotoxin. In fact, all strains were able to produce TeA, the benzopyrone derivatives (AOH, AME and ALT) were synthesized by almost the same strains. AOH and AME were produced by more than $70 \%$ of the strains, with some differences in the concentrations. Ruc PMP 4 belonging to clade 2 produced only TeA.

\section{Discussion}

Within the genus Alternaria, taxonomy is rather complex and species differentiation is usually based on a combination of morphological observations and molecular characterization (Simmons, 2007). However, especially within the small-spored Alternaria species, a large variation in morphological aspects was observed depending mainly on growth conditions, and even with molecular methods species identification is difficult (Andersen et al., 2009). In some cases, separation has been achieved at species-group level (Andersen et al., 2002; Polizzotto et al., 2012). Lawrence et al. (2013) identified A. arborescens and the A. tenuissima speciesgroups together with A. alternata into one section, with more than 50 additional species that were not always correlated with the species-group based on morphological characters (Woudenberg et al., 2013). More recently, Woudenberg et al. (2015) have identify A. arborescens species complex, whereas A. alternata and A. tenuissima have been joined together in the section Alternaria. In our experimental setup based on $\beta$-tubulin sequences, we found two big groups of isolates, the first including A. alternata, A. arborescens and A. tenuissima, and the second 
closely related to A. japonica. Interestingly, no isolate close to the A. brassicae was found, while only one isolate was related to A. brassicicola (isolate Ruc PMP 4 obtained from rocket). In most cases, three Alternaria species (A. brassicicola, A. brassicae and A. japonica) have been reported as the causal agents of black spot disease of crucifers (Peruch et al., 2006; Reis and Boiteux, 2010, Gilardi et al., 2015). Also, Aneja et al. (2014) described $A$. brassicae, A. brassicicola and A. alternata to be present on oilseed Brassicas with A. brassicae as a dominant species. However, A. tenuissima was found as a principal species on cabbage in Iran (Rahimloo and Ghosta, 2015).

In general, morphological observations and in particular the sporulation pattern confirmed the results obtained by phylogenetic analysis (clustering) except for isolate Cav 7/10 that featured an atypical morphological aspect. However, there were no statistical differences between different clusters when mean conidia size was considered.

Our results show that Alternaria isolates from rocket and cabbage plants are able to infect their original host with different levels of virulence. A. japonica was found to be the most prevalent specie within the isolates of Alternaria from wild and cultivated rocket plants and seeds, however A. tenuissima, A. brassicicola and A. arborescens have been here also identified. The results of the present study suggest that these species are a potential threat of rocket. However, it is well known the broad range of hosts from which these species may be isolated (Neergaard, 1945; Simmons 2007, Farr and Rossman, 2016).

At the same time, almost all isolates were able to produce at least three different mycotoxins under in vitro conditions. However, there was no clear correlation between virulence and mycotoxin production. In a wide range of plant pathogens, virulence level has been described to be independent of mycotoxin production, whereas virulence have been associated to mycotoxin production for other plant pathogens: Desjardins et al (1989) have demonstrated the essential role of thrichotecene 2 during pathogenesis of Fusarium sporotrichioides. In their experiments, the authors showed that a mutation blocking the T2 toxin biosynthesis resulted in a non-pathogenic phenotype, whereas pathogenicity was restored when the same mutant was complemented by the wild type. In Alternaria spp., the possible role of mycotoxins on virulence and/or pathogenicity was investigated in a study on the impact of osmotic stress on tomato that revealed that $\mathrm{AOH}$ biosynthesis is an important factor that supporting the tissue colonization of tomatoes (Graf et al., 2012, Geisen et al., 2015). Most isolates of our study produced TeA in vitro confirming results obtained in our previous work (Siciliano et al., 2015). In fact, TeA contamination at rather high levels of tomatoes grown in southern Italy can be

\section{ins-AperTO}


a major issue, while alternariol and alternariol methyl ether were present at lower levels (Botalico and Logrieco, 1998). Stinson et al. $(1980 ; 1981)$ reported a high level of tenuazonic acid in infected tomatoes.

Mycotoxin production depends on several factors (Sanchis and Magan, 2004). Water activity (aw) played an important role for the TeA, AME and $\mathrm{AOH}$ production in A. alternata with an optimum value greater than 0.97 . Furthermore, temperature affected mycotoxin production by A. alternata in synthetic medium with an optimum around $28^{\circ} \mathrm{C}$ for $\mathrm{AOH}$ and AME and $21^{\circ} \mathrm{C}$ for TEA (Hasan, 1996). Moreover, AOH production has been shown to be influenced by light exposure with a reduced mycotoxin production compared to cultures grown in the dark (Häggblom, 1979; 1986). Finally, cultivation conditions, in particular carbon and nitrogen sources can influence mycotoxin production by A. alternata (Brzonkalik et al., 2011). Thus, mycotoxin production under natural conditions is strongly influenced by the species and cultivar of host plants, by growth, harvesting and environmental conditions (Lauren and Thaer, 2008). For all these reasons, it is not surprising that there was no obvious correlation between our in vitro mycotoxin and virulence data set. 


\section{References}

Andersen, B., Sørensen, J.L., Nielsen, K.F., van den Ende, B.G., de Hoog, S. (2009). A polyphasic approach to the taxonomy of the Alternaria infectoria species-group. Fungal Genetics and Biology, 46, 642-656.

Andersen, B., Krøger, E., Roberts, R.G. (2002). Chemical and morphological segregation of Alternaria arborescens, A. infectoria and A. tenuissima species-groups. Mycological Research, 106, 170-182.

Aneja, J.K., Agarwal, A.A., Agnihorti, A.A. (2014). Inter and intra-specific diversity in Alternaria species infecting oilseed Brassicas in India. Journal of Oilseed Brassica, 5, 102-117.

Bessadat, N., Simoneau, P., Benichou, S., Setti, B., Kihal, M., Henni, D.E. (2014). Morphological, physiological and pathogenic variability of small-spore Alternaria sp. causing leaf blight of Solanaceous plants in Algeria. African Journal of Microbiology Research, 8, 3422-3434.

Bottalico, A., Logrieco, A. (1998). Toxigenic Alternaria species of economic importance. In K.K. Sinha and D. Bhatnagar (Eds), Mycotoxins in Agriculture and Food Safety (pp. 65-108) New York: Marcel Dekker.

Brzonkalik, K., Herrling, T., Syldatk, C., Neumann, A. (2011). The influence of different nitrogen and carbon sources on mycotoxin production in Alternaria alternata. International Journal of Food Microbiology, 147, 120-126.

CABI (2007). Crop Protection Compendium, 2007 Edition, Wallingford UK: CABI International.

Desjardins, A.E., Spencer, G.F., Plattner, R.D., Beremand, M.N. (1989). Furanocoumarin phytoalexins, trichothecene toxins, and infection of Pastinaca sativa by Fusarium sporotrichioides. Phytopathology, 79, 170175.

Farr, D. F., Rossman, A.Y. (2016). Fungal Databases - Fungal Databases, Systematic Mycology and Microbiology Laboratory. ARS, USDA.

Gannibal, P.B., Orina, A.S., Mironenko, N.V., Levitin, M.M. (2014). Differentiation of closely related species, Alternaria solani and A. tomatophila, by molecular and morphological features and aggressiveness. European Journal of Plant Pathology, 139, 609-623.

Garibaldi, A., Gilardi, G., Bertoldo, C., Gullino, M.L. (2011). First report of leaf spot of wild (Diplotaxis tenuifolia) and cultivated (Eruca vesicaria) rocket caused by Alternaria japonica in Italy. Plant Disease, 95, 1316.

Geisen R., Graf, E., Schmidt-Heydt, M. (2015). HogA and PacC regulated alternariol biosynthesis by Alternaria alternata is important for successful substrate colonization. Acta Horticulturae 1144, 141-148.

\section{ins-AperTO}


Gilardi, G., Demarchi, S., Ortu, G., Gullino, M.L., Garibaldi, A. (2015). Occurrence of Alternaria japonica on seeds of wild and cultivated rocket. Journal of Phytophatology, 163, 419-422.

Graf, E., Schmidt-Heydt, M., Geisen R. (2012). HOG MAP kinase regulation of alternariol biosynthesis in Alternaria alternata is important for substrate colonization. International Journal of Food Microbiology, 157, 353-359.

Häggblom, P., Niehaus, W.G. (1986). Light effects on polyketide metabolism in Alternaria alternata. Experimental Mycology, 10, 252-255.

Häggblom, P., Unestam, T. (1979). Blue light inhibits mycotoxin production and increases total lipids and pigmentation in Alternaria alternata. Applied and Environmental Microbiology, 38, 1074-1077.

Hasan, H.A. (1996). Alternaria mycotoxins in black rot lesion of tomato fruit: Conditions and regulation of their production. Acta Microbiologica et Immunologica Hungarica Journal, 43, 125-133.

Humpherson-Jones, F. M. (2007). The incidence of Alternaria spp. and Leptosphaeria maculans in commercial Brassica seed in the United Kingdom. Plant Pathology, 34, 385-390.

Humpherson-Jones, F.M. (1989). Survival of Alternaria brassicae and Alternaria brassicicola on seed debris of oilseed rape and cabbage. Annals of Applied Biology, 115, 45-50.

Humpherson-Jones, F.M., Maude, R.B. (1982). Studies on the epidemiology of Alternaria brassicicola in Brassica oleracea seed production crops. Annals of Applied Biology, 100, 61-71.

Kohl, J., van Tongeren, C.A.M., Groenenboom-de Haas, B.H., van Hoof, R.A., Driessen, R., van der Heijden, L. (2010). Epidemiology of dark leaf spot caused by Alternaria brassicicola and A. brassicae in organic seed production of cauliflower. Plant Pathology, 59, 358-367.

Kolte, S.J., Awasthi, R.P., Vishwanath (1987). Assessments of yield losses due to Alternaria blight in rapeseed and mustard. Indian Phytopathology, 40, 209-211.

Lauren, S.J., Fadwa, A.T. (2008). Factors affecting mycotoxin production in fruits. In R. Barkai-Golan and N. Paster (Eds.) Mycotoxins in Fruit and Vegetables (pp. 75-104) London: Academic Press Is an Imprint of Elsevier.

Lawrence, D.P., Gannibal, P.B., Peever, T.L., Pryor, B.M. (2013). The sections of Alternaria: formalizing speciesgroups concepts. Mycologia, 105, 530-546.

Mac Kinon, S.L., Keifer, P., Ayer, W.A. (1999). Components from the phytotoxic extracts of Alternaria brassicicola, a black spot pathogen of canola. Phytochemistry, 51, 215-221

Mathur, R.S., Sarboy, A.K. (1977). Physiological studies on Alternaria alternata from sugar beet. Indian Journal Phytopathology, 30, 432-434.

\section{ins-AperTO}


Maude, R.B., Humpherson-Jones, F.M. (1980). Studies on the seed-borne phases of dark leaf spot (Alternaria brassicicola) and grey leaf spot (Alternaria brassicae) of brassicas. Annals of Applied Biology, 95, 311-327.

Neergaard, P. (1945). Danish Species of Alternaria and Stemphylium. London, UK: Oxford University Press. of oilseed rape and cabbage. Annals of applied Biology, 115, 45-50.

Ostry, V. (2008). Alternaria mycotoxins: An overview of chemical characterization, producers, toxicity, analysis and occurrence in foodstuffs. World Mycotoxins Journal, 1, 175-188.

Peruch, L.A.M., Michereff, S.J., Araújo, I.B. (2006). Survey of the intensity of Alternaria black spot and black rot on brassica species under organic farming systems in Pernambuco and Santa Catarina states, Brazil. Horticultura Brasileira, 24(4), 464-469.

Polizzotto, R., Andersen, B., Martini, M., Grisan, S., Assante, G., Musetti, R. (2012). A polyphasic approach for the characterization of endophytic Alternaria strains isolated from grapevines. Journal of Microbiological Methods, 88, 162-171.

Rahimloo, T., Ghosta, Y. (2015). The occurrence of Alternaria species on cabbage in Iran. Žemdirbystė (Agriculture), 102(3), 343-350.

Reis, A., Boiteux, L.S. (2010). Alternaria species infecting Brassicaceae in the Brazilian neotropics: geographical distribution, host range and specificity. Journal of Plant Pathology, 92(3), 661-668

Rossman, S.N., Cernoch, P.L., Davis, J.R. (1996). Dematiaceous fungi are an increasing cause of human disease. Clinical Infectious Diseases, 22, 73-80.

Rotem, J. (1994). The genus Alternaria: biology, epidemiology, and pathogenicity. St Paul, USA: American Phytopathological Society.

Sanchis, V., Magan, N. (2004). Environmental conditions affecting mycotoxins. In N. Magan and M. Olsen (Eds.) Mycotoxins in Food: Detection and Control (pp. 174-189) Cambridge, UK: Woodhead Publishing.

Siciliano, I., Ortu, G., Gilardi, G., Gullino, M.L., Garibaldi, A. (2015). Mycotoxin production in liquid culture and on plants infected with Alternaria spp. isolated from rocket and cabbage. Toxins, 7, 743-754.

Simmons, EG. (2007). Alternaria: An Identification Manual. APS PRESS, St Paul, MN, USA.

Singh, R.C., Mohan, C., Sharma, V.K. (2012). Morphological and pathological variations in isolates of Aletrnaria brassicae causing leaf blight of rapeseed and mustard. Plant Disease Resistance, 27, 22-27.

\section{ins-AperTO}


Stinson, E.E., Bills, D.D., Osman, S.F., Siciliano, J., Ceponis, M.J., Heisler, E.G. (1980). Mycotoxin production by Alternaria species grown on apples, tomatoes and blueberries. Journal of Agricultural and Food Chemistry, $28,960-963$.

Stinson, E.E., Osman, S.F., Heisler, E.J., Siciliano, J., Bills, D.D. (1981). Mycotoxin production in whole tomatoes, apples, oranges and lemons. Journal of Agricultural and Food Chemistry, 29, 790-792.

Van der Waals, J.E., Korsten, L., Slippers, B. (2004). Genetic diversity among Alternaria solani isolates from potatoes in South Africa. Plant Disease, 88, 959-964.

Vannacci, G., Harman, G.E. (1987). Biocontrol of seed-borne Alternaria raphani and A. brassicicola. Canadian Journal of Microbiology, 33, 850-856.

Woudenberg, J.H.C., Groenewald, J.Z., Binder, M., Crous, P.W. (2013). Alternaria redefined. Studies in Mycology, $75,171-212$.

Woudenberg, J.H., Seidl, M.F., Groenewald, J.Z., de Vries, M., Stielow, J.B., Thomma, B.P., Crous, P.W. (2015). Alternaria section Alternaria: Species, formae speciales or pathotypes? Studies in Mycology, 82, 1-21. 


\section{Table captions}

Table 1 Isolates of Alternaria spp. obtained from leaves of different hosts in northern Italy with accession numbers of $\beta$-tubulin gene deposited on Genbank. ( $\mathrm{CN}=\mathrm{Cuneo}$ province; $\mathrm{TO}=$ Torino province; $\mathrm{AT}=\mathrm{Asti}$ province)

\begin{tabular}{|c|c|c|c|}
\hline Isolate oxde & Host & Farm of origin, province & Accessicn mumber \\
\hline Cav 2/10 & Cunliflower ov. White exoell & CReSOExperimental center, Boves (ON) & KT920427 \\
\hline Cav 3/10 & Cabbage cv. Mcama & Pasglieno- Mancalieri(TO) & KT920426 \\
\hline Cav $5 / 10$ & Cabhage cv.Estaryl & Porcellana (AT) & KT920423 \\
\hline Cav. $7 / 10$ & Cabhage cv. Mcama & Sxcheto G.Savigliano (CN) & KT920425 \\
\hline Cav. $12 / 10$ & Cunliflower ov. White exoell & Dutto-Ciordanengo-Boves (CN) & KT920424 \\
\hline Cav. $15 / 10$ & Cabhage cv. Dame & CReSOExperimental center, Boves (ON) & KT920428 \\
\hline Rac 1/10 & Cultivited rocket & Barnuta-tunnel IMcrocalieri (TO) & K.J909926 \\
\hline $\operatorname{Rac} 2 / 10$ & Cultivised rocket & Bsgnolo (TO) & KT920415 \\
\hline $\operatorname{Rac} 4 / 10$ & Wild rocket cv. Fastaglints & Alhanga (SV) & KT9204 I3 \\
\hline Rave $5 / 10$ & Cultivited rocket & Barnuto-tunel 1, Mancalieri (TO) & KT9204 I2 \\
\hline Rav $6 / 10$ & Cul tivited rocket & Barnuto-tunnel 3, Mancalieri (TO) & KT920414 \\
\hline Rax $9 / 10$ & Oul tiv ted rocket & Bernuto-tunnel 8, Mancalieri (TO) & KT9204 II \\
\hline $\operatorname{Rac} 12 / 10$ & Cul tivited rocket & Barnuta-tunel 8, Mancalieri (TO) & KT9204I7 \\
\hline $\operatorname{Rac} 13 / 70$ & Cul tivited rocket & Barnuta-tmnel \&, Mancalieri (TO) & KT9204I6 \\
\hline $\operatorname{Rac} 1 / 11$ & Wild rocket & Barnun, Mancalieri (TO) & K.J909927 \\
\hline
\end{tabular}

CN Cuneo province, TO Tonino province, AT Astiprovine 
Table 2 Isolates of Alternaria spp. obtained from seeds of different hosts with accession numbers of $\beta$-tubulin gene deposited on Genbank. ( $\mathrm{FC}=$ Forlì-Cesena province; $\mathrm{VE}=$ Venezia province; $\mathrm{BG}=$ Bergamo province)

\begin{tabular}{|c|c|c|c|}
\hline Isolste code & Horst & Origin (seal ccennuny) & Accessicn mumber \\
\hline Rac PMP 4 & Culivisal rodket & Cesena (FC), Ituly & KT920420 \\
\hline Rac PMP 8 & Cultivisal rodket & Cesena (FC), Ituly & KT920479 \\
\hline Rac PMP 9 & Culivisal rodket & Cesena (FC), Italy & KT920418 \\
\hline Rac PMP 12 & Culivital rodket & Cesena (FC), Ituly & KT920422 \\
\hline Rax PMP 19 & Culivital rodket & Cesena (FC), Ituly & KT92042I \\
\hline Rax PMP $19 j$ & Culivital rodket & Cesena (FC), Italy & K.J909928 \\
\hline $360-4 \mathrm{NL}$ & Wild rodket & Vegetzble sød (VE), Ely & $K / 909929$ \\
\hline $37 \mathrm{Q}-13 \mathrm{NL}$ & Wild nodket & Vegetzhle sod (VE), Ely & KJ 8893443 \\
\hline $37 \mathrm{Q}-16 \mathrm{NL}$ & Wild odket & Vegetable seod (VE), Ealy & K.J909930 \\
\hline $37 \mathrm{Q}-22 \mathrm{NL}$ & Wild nodret & Vegetable sood (VE), Ealy & KJJ82344I \\
\hline $38 \mathrm{Q}-1 \mathrm{NL}$ & Wild rodket & Marzocchi, Lodi, Italy & K.J883442 \\
\hline $38 \mathrm{Q}-9 \mathrm{NL}$ & Wild rodket & Mazzocchi, Lodi, Italy & KJ \\
\hline $38 \mathrm{Q}-19 \mathrm{NL}$. & Wild rodket & Mazzocchi, Lodi, Italy & K.J909932 \\
\hline $43 \mathrm{Q}-1 \mathrm{NL}$ & Wild rodiet & Orosan, Azzno (BG), Ely & KJ J893440 \\
\hline $43 \mathrm{Q}-2 \mathrm{NL}$ & Wild rodket & Orcsan, Azzno (BG), Ely & K./909933 \\
\hline
\end{tabular}

Table 3 Accession numbers of $\beta$-tubulin gene deposited on Genbank of CBS strains used in this work.

\begin{tabular}{|c|c|c|}
\hline Isolates & Sppacie & Accessicn munbess \\
\hline CAs 239.73 & Aitonaia brascicae & ท77074.I \\
\hline KCPM $1120-77$ & Altonaria brascicicala & Y77084.I \\
\hline CBS 124278 & Alitanaia schuirsima & KT920410 \\
\hline CBS 124274 & Alitonaria abansacns & KT 920429 \\
\hline CBS 115152 & Aiftonaria alsemata & KT920430 \\
\hline CBS 118390 & Alitonaria jugonica & KJ883438 \\
\hline CBS 191.86 & Pleagpana hohaym & AYr749032.I \\
\hline
\end{tabular}


Table 4 Identity, sporulation group, virulence and mycotoxin production of Alternaria isolates obtained from different hosts.

\begin{tabular}{|c|c|c|c|c|c|c|}
\hline Isolate & $\begin{array}{l}\text { Alikenaria species } \\
\text { hers an } \beta \text {-tubulin }\end{array}$ & $\begin{array}{l}\text { Alsornaia spacies } \\
\text { based on motphology }\end{array}$ & $\begin{array}{l}\text { Sponulation } \\
\text { group }\end{array}$ & Host & Vinulence" & Mycotoxins \\
\hline Rac $1 / 10$ & japanica & jupanica & - & Cul tivated rocket & $\mathrm{H}$ & TeA, AOH, AME, ALT \\
\hline $\operatorname{Rac} 2 / 10$ & altanasa monplex & ailemasa & 4 & Cul tivated rocket & H & TeA, AOH, AME, ALT \\
\hline $\operatorname{Pac} 4 / 10$ & altenasa mmpriex & Nock testad & Not testad & Cul tivated rocket & M & TeA, AOH, AME \\
\hline Rac 5/10 & altanata mmyplex & apharescens & 3 & Cul tivated rocket & M & TeA, AOH, AME \\
\hline Rac $6 / 10$ & altenata monplex & Noctestad & Not testal & Cul tivated rocket & M & $\operatorname{TeA}$ \\
\hline Ruc $9 / 10$ & aitenasz mmyplex & athanescens & 3 & Cul tivated rocket & M & TeA, AOH, AME, ALT, TEN \\
\hline Rac $12 / 0$ & altenasa onspiex & arharescens & 3 & Cul tivated rocket & M & TeA, AOH, AME, ALT, TEN \\
\hline Rac 13/10 & altenasa monplex & sonuissima & 5 & Not tested & Not testal & TeA, AOH, AME, ALT \\
\hline Rac 1/11 & japanica & japanica & - & Not tested & Not testad & - \\
\hline Ruc PMP 4 & brascicicala & brassicimla & 5 & Cul tivated rocket & M & TeA \\
\hline Rac PMP 8 & altemasa monpiex & alemasa & 4 & Cul tivated rocket & L. & TeA \\
\hline Rac PMP 9 & alternasa monplex & alvemasa & 4 & Cul tivated rocket & L. & TeA, AOH, AME, ALT \\
\hline Rac PMP 12 & alternats compricx & aikenasz & 4 & Cul tivated rocket & M & TeA, AOH, AME, ALT \\
\hline Rac PMP 19 & Alitenata momplex & brassicinae & 5 & Cul tivated rocket & M & TeA, AOH, AME, ALT, TEN \\
\hline Ruc PMP $19 \mathrm{~J}$ & japonina & Not tested & Not tatal & & & TeA \\
\hline Cav $2 / 10$ & ait onasa momplex & aibemass & 4 & Caul iflower & M & TeA, AOH, AME, ALT \\
\hline Cav 3/10 & alternata omprolex & sonuissima & 5 & Cabhage & $\mathrm{H}$ & TeA \\
\hline Cav 5/10 & alternats monylex & aphanescens & 3 & Cabbage & H & TeA, AOH, AME, ALT \\
\hline Cav 7/10 & aitornasa monplex & brassicinae & 5 & Cabhage & M & TeA, AOH, AME, ALT \\
\hline Cav $12 / 10$ & altornata monpicx & scnuisrima & 5 & Cauliflower & $\mathrm{H}$ & TeA, AOH, AME, ALT, TEN \\
\hline Cav $15 / 10$ & alternata monpiex & scnuissima & 5 & Cabbage & M & TeA, AOH, AME, ALT \\
\hline $36 Q^{-4} \mathrm{NL}$ & japonica & Not tested & Not tental & Wild rocket & $\mathrm{H}$ & - \\
\hline 37Q-13 NL. & japonica & Not tested & Not tated & Wild rocket & M & - \\
\hline $37 \mathrm{Q}-16 \mathrm{NL}$ & japanica & japonina & - & Wild rocket & M & $=$ \\
\hline $37 \mathrm{Q}-22 \mathrm{NL}$ & jupanica & Not tested & Not tastal & Wild rocket & M & - \\
\hline $38 Q-1 \mathrm{NL}$ & japanica & japonica & - & Wild rocket & H & TeA, AOH, AME, ALT \\
\hline $38 \mathrm{Q}-9 \mathrm{NL}$ & japanica & japonica & $=$ & Wild rocket & M & - \\
\hline $38 \mathrm{Q}-19 \mathrm{NL}$ & japanica & japonica & - & Wild rocket & M & - \\
\hline 430-INL. & japonica & japonica & - & Wild rocket & H & - \\
\hline $43 \mathrm{Q}-2 \mathrm{NL}$ & japanica & japonica & - & Wild rocket & M & - \\
\hline
\end{tabular}

"L, low vinulence (10-30\% of infected laves); M, moderate vinulence (31-60\% of infected leaves); H, high virulence (61-100\% of infected leaves)

${ }^{a}$ L, low virulence $(10-30 \%$ of infected leaves); M, moderate virulence (31-60\% of infected leaves); $\mathrm{H}$, high virulence $(61-100 \%$ of infected leaves) 
Table 5 Size of conidia ( $\mu \mathrm{m}$, mean in parenthesis) of Alternaria spp. on PCA media.

No conidia were developed for Ruc 6/10. No microscopic observations for 37Q-22NL; 37Q-13 NL; 36Q-4 NL; Ruc PMP 19. ${ }^{*}$ Sporulation groups according to Simmons and Roberts $(1993) \cdot{ }^{* *}$ Conidia mainly solitary o with chains of 2-3 spores

\begin{tabular}{|c|c|c|c|c|c|}
\hline \multirow[t]{2}{*}{ Sench } & \multirow{2}{*}{$\frac{S a x=\pi n}{W S k}$} & \multicolumn{2}{|l|}{ Ninter of segta } & \multirow[t]{2}{*}{ Ghapdbąक } & \multirow[t]{2}{*}{ Spoetiston gropp" } \\
\hline & & Tnowersal & Loquodinal & & \\
\hline Car 1228 & $51-124 a 5=28\}$ & $3-3146=1.6$ & $0105=05)$ & & 5 \\
\hline Cor Laste & $51-12686=199$ & $2-7(4.0=15)$ & $02(205=06)$ & & 5 \\
\hline$k \times 1 / 0$ & $42-4(2.8=18)$ & $3-649=1.37$ & $03(26=10)$ & & . \\
\hline $\bar{k} \mathbf{x}$ inii & 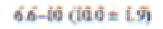 & 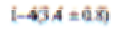 & 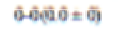 & 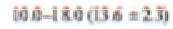 & . \\
\hline$R \times 210$ & $56-130$ (25 $=19$ ) & $2-503=099$ & $\theta-(02=0,4)$ & & 4 \\
\hline$k \times s$ sie & $29-84 C 0=169$ & $3-7(46=1.5)$ & $0.2(02=0.4)$ & & 3 \\
\hline$R \propto \mathbb{Y}_{10}$ & $60-33 a A=06$ & $3-6(4.1=0.8)$ & $Q-1(a)=0.3)$ & & 3 \\
\hline$x \times 12 A \theta$ & $35-10.205=18)$ & $4-3 \beta \theta=123$ & $0-1(02=04)$ & & 3 \\
\hline $\bar{k}=13.90$ & $66-11002+11)$ & $3-360=159$ & $0-2(08=07)$ & & 5 \\
\hline Ra Fen 4 & $60-14186=153$ & $|-5| a|=| 3 \mid$ & $\theta(2)=03)$ & & 5 \\
\hline Rarnes & $52-2103=1.5)$ & $4-7(49=16)$ & $0.3(07=0.8)$ & & 4 \\
\hline R× rMe 9 & $53-11(0.2=12)$ & $4-7(46=1)$ & $0-3(06=08)$ & & 4 \\
\hline$k \times \operatorname{Re} 12$ & $62-8(69=0.5)$ & $3-60.7=169$ & $0-\{(01=0 A)$ & & 4 \\
\hline $3 \times 0-16 \mathrm{~N}$. & $62-85(78=05)$ & $2-503=09$ & $0-i(10=03)$ & $119-152(136=10$ & $=$ \\
\hline $390-1 \mathrm{NL}$ & $59-2.8(66=0.5)$ & $5-7(4.2=12)$ & $0-105=0.5)$ & $82-132(11.1=L 4$ & . \\
\hline $3909 \times 1$. & $59-94(24=13)$ & $3-7(4.7 \pm 1.3)$ & $0-3(29 \pm 09)$ & $21-141(127=69)$ & - \\
\hline $390-19 \mathrm{NL}$ & $6.1-29 \mathrm{a} .1=06$ & $4-763=1.21$ & Q $-105=05)$ & $104-166014.1=19$ & . \\
\hline 4Nopl. & $69-118.4=12)$ & $2-6(41=12)$ & $02(29=08)$ & $\begin{array}{l}10-172 \\
025=20)\end{array}$ & - \\
\hline $450-21$ & $58-8769=47$ & $2-6(4.4=1.23$ & $0-(05=05)$ & $11.2-15.40(138=23)$ & - \\
\hline hap 19 & $42-10 \propto(1=15)$ & $3-7(46)=169$ & $0-(04=05)$ & & 5 \\
\hline casusis & $47-11.96 .9=13)$ & $4-351=13$ & $1 \rightarrow 303=19$ ) & & 5 \\
\hline CBS1L3Do & $52-2.8(6.4=07)$ & $3-7(49=169$ & $0-(03=05)$ & & . \\
\hline C1612e24 4 & $66-10(2.6=093)$ & $3-609=47$ & $Q-102=0,4\}$ & & 3 \\
\hline Св54-016 & $55-8900=123$ & $3-609=07$ & $02(03=0.6)$ & & \\
\hline
\end{tabular}

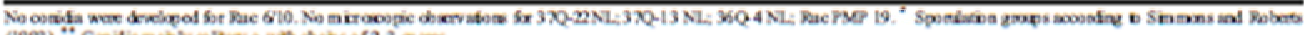




\section{Figure caption}

Fig. 1 Phylogenetic relatedness (tree) of Alternaria spp. based on $\beta$-tubulin gene and analyzed by Maximum Likelihood method.

The evolutionary history was inferred by using the Maximum Likelihood method based on the Kimura 2parameter model. The tree with the highest log likelihood $(-3253.8466)$ is shown. The percentage of trees in which the associated taxa clustered together is shown next to the branches. Initial tree(s) for the heuristic search were obtained by applying the Neighbor-Joining method to a matrix of pairwise distances estimated using the Maximum Composite Likelihood (MCL) approach. All positions with less than $95 \%$ site coverage were eliminated

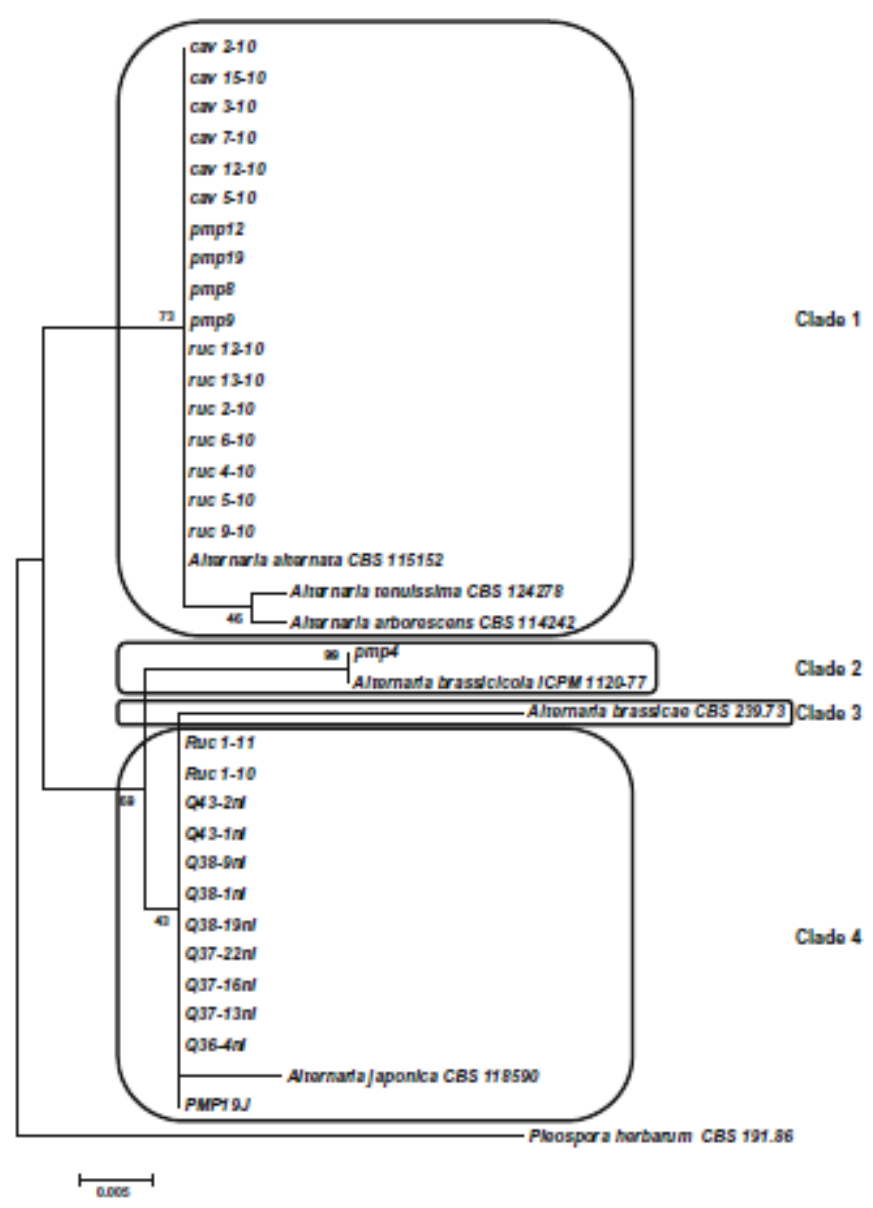


Fig. 2 Length of conidia body and beak of Alternaria sp. isolates obtained on PCA media.

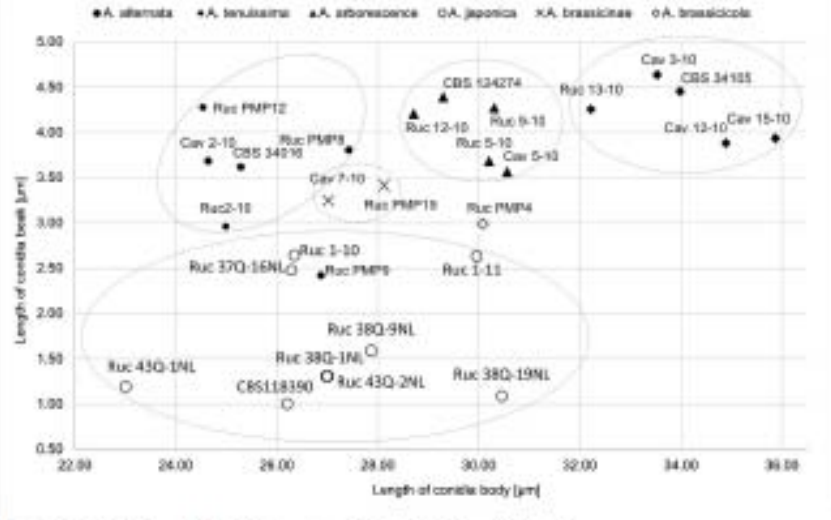

\section{ins-AperTO}

University of Turin's Institutional Resea rch Information System and O pen Access Institutiona I Repository 
Fig. 3 Mycotoxin production of Alternaria sp. isolates obtained on inductive media incubated at $28{ }^{\circ} \mathrm{C}$ for 8 days in the dark.

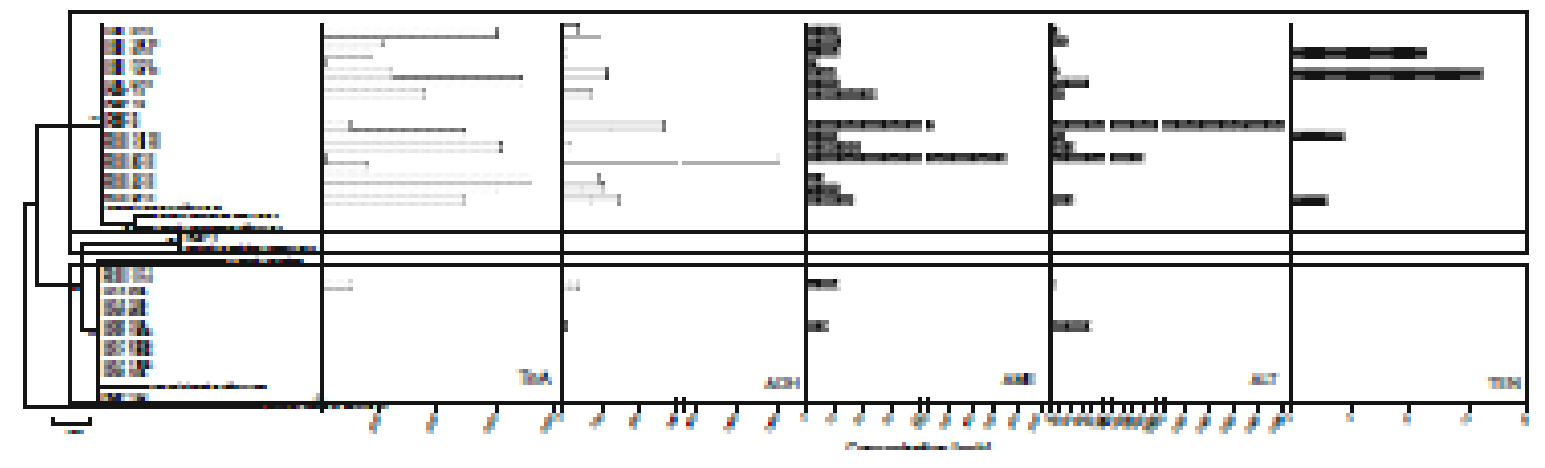

